\title{
Intrigues of biofilm: A perspective in veterinary medicine
}

\author{
Umar Faruk Abdullahi ${ }^{1}$, Ephraim Igwenagu² ${ }^{2}$ Anas Mu'azu ${ }^{3}$, Sani Aliyu³ and Maryam Ibrahim Umar
}

1. Department of Postgraduate, Faculty of Medicine, Universiti Sultan Zainal Abidin, Kuala Terengganu, Malaysia; 2. Department of Veterinary Pathology, University of Maiduguri, Maiduguri, Nigeria; 3. Department of Microbiology, Faculty of Medicine, Universiti Sultan Zainal Abidin, Kuala Terengganu, Malaysia.

Corresponding author: Umar Faruk Abdullahi, e-mail: docfaroukxy@yahoo.com, EI: ephraimigwe@gmail.com, AM: anasinmuazu1@yahoo.com, SA: sanialiyu32@gmail.com, MIU: maryamiumar@gmail.com

Received: 12-09-2015, Revised: 19-11-2015, Accepted: 29-11-2015, Published online: 02-01-2016

doi: 10.14202/vetworld.2016.12-18 How to cite this article: Abdullahi UF, Igwenagu E, Mu'azu A, Aliyu S, Umar MI (2016) Intrigues of biofilm: A perspective in veterinary medicine, Veterinary World 9(1): 12-18.

\begin{abstract}
Biofilm has a tremendous impact in the field of veterinary medicine, especially the livestock industry, leading to a serious economic loss. Over the years, little attention has been given to biofilm in animals with most of the research geared toward human biofilm diseases. The greatest challenge posed by biofilm is in its incredible ability to resist most of the currently existing antibiotics. This mystery can best be demystified through understanding the mechanism of the quorum sensing which regulate the pathophysiology of biofilm. Ability of biofilm formation in a variety of inanimate surfaces such as animal food contact surfaces is responsible for a host of biofilm diseases affecting animals and humans. In this review, we highlighted some of the challenges of biofilm in livestock and food industries. Also highlighted are; mechanisms of biofilm development, best diagnostic approach and possible novel therapeutic measures needed to combat the menace of biofilm in veterinary medicine.
\end{abstract}

Keywords: antibiotic resistance, biofilm, contact surfaces, quorum sensing, veterinary medicine.

\section{Introduction}

Biofilm-associated diseases pose serious health challenges to the animal kingdom, resulting in high economic losses in the livestock industry [1,2]. It is suggested to be responsible for about $80 \%$ of infectious diseases affecting animal and human, hence the impact in veterinary medicine cannot be ignored. Pathophysiology of the most biofilm infections in animal are similar to that of human, according to previous studies, approximately $61 \%$ of human biofilm infections are of zoonotic origin [3], thus, underscores the importance of biofilm in veterinary medicine and the need to come up with a robust treatment and preventive plan toward combating the scourge. Few examples of common zoonotic biofilm infections include; chronic wound resulting from dog bite injury. The increased chronicity of wound following a dog bite injury is connected to the pathogenic effect of numerous biofilm organisms in the oral cavity of the dog [4]. Another example is canine uropathogenic Escherichia coli infection which affects the human urinary system; this bacterial biofilm has been experimentally demonstrated to induce cytotoxicity in human bladder epithelial cells [5]. Other common zoonotic biofilm is highlighted in the list of animal biofilm diseases (Table-1). In this review, we highlighted some of the challenges of biofilm in livestock and food industries.

Copyright: Abdullahi et al. Open Access. This article is distributed under the terms of the Creative Commons Attribution 4.0 International License (http://creativecommons.org/licenses/ by/4.0/), which permits unrestricted use, distribution, and reproduction in any medium, provided you give appropriate credit to the original author(s) and the source, provide a link to the Creative Commons license, and indicate if changes were made. The Creative Commons Public Domain Dedication waiver (http:// creativecommons.org/publicdomain/zero/1.0/) applies to the data made available in this article, unless otherwise stated.
Also highlighted are; mechanisms of biofilm development, best diagnostic approach and possible novel therapeutic measures needed to combat the menace of biofilm in veterinary medicine.

\section{Development of Biofilm}

Biofilm formation is a complex process, occurring as a cascade of molecular and physiological events. It can be classified into five distinct stages, which includes: (1) Development of a surface conditioning film, (2) reversible and irreversible attachment of cells to a surface, (3) formation of microcolonies, (4) maturation and differentiation of the biofilm with the expression of matrix polymers, and (5) dispersal of cells from the biofilm [6-8]. The mechanism of biofilm formation (Figure-1).

\section{Development of a Surface Conditioning Film}

Surface conditioning film is a complex surface consisting of polysaccharides, glycoproteins, and humic compounds [9-11]. It serves as the platform for surface adherence of microorganism, hence, seen as pre-requisite to the attachment stage. The conditioning film playsa key role in modifying the physical and chemical properties of the substratum, as well as providing a concentrated nutrient source and important trace elements [11]. However, components of blood, tears, urine, saliva, intravascular fluid and respiratory secretions in an animal can also contribute to conditioning film. Within the natural environment, microorganism does not adhere directly to a substratum, rather, they adhere to a conditioning film which is known to form on much substrata, Figure-1 demonstrates the role of conditioning film in biofilm development $[11,12]$. 
Table-1: Common biofilm diseases in veterinary medicine.

\begin{tabular}{|c|c|c|c|c|}
\hline $\mathbf{S} / \mathbf{N}$ & Diseases & Common aetiology & Most affected host & Reference \\
\hline 1 & Mastitis & Streptococcus Agalactiae \& Staphylococcus aureus & Domestic ruminants & {$[67-69]$} \\
\hline 2 & Jones disease & Mycobacterium avium sub specie paratuberculosis & Small ruminants & {$[70,71]$} \\
\hline 3 & Pnumonia & Pasturella multicida & Avian and ruminants & {$[72]$} \\
\hline 4 & Caseous Lymphadinitis & Coryenobacterium pseudotuberculosis & Small ruminants & [73] \\
\hline 5 & Liver abscess & Fusobacterium necrophorum & Domestic ruminant & {$[74]$} \\
\hline 6 & Wound infection & Staphylococcus aureus \& Pseudomonas spp & Equine & {$[67,68,75,76]$} \\
\hline 7 & Enteritis & Escherichia coli \& Salmonella spp & All domestic animals & {$[1]$} \\
\hline 8 & Urinary tract infection & Escherichia coli & Dogs & [77] \\
\hline 9 & Pyometra & Escherichia coli & Dogs & [78] \\
\hline 10 & Periodontal disease & Staphylococcus spp & Dogs \& Cats & {$[4]$} \\
\hline
\end{tabular}

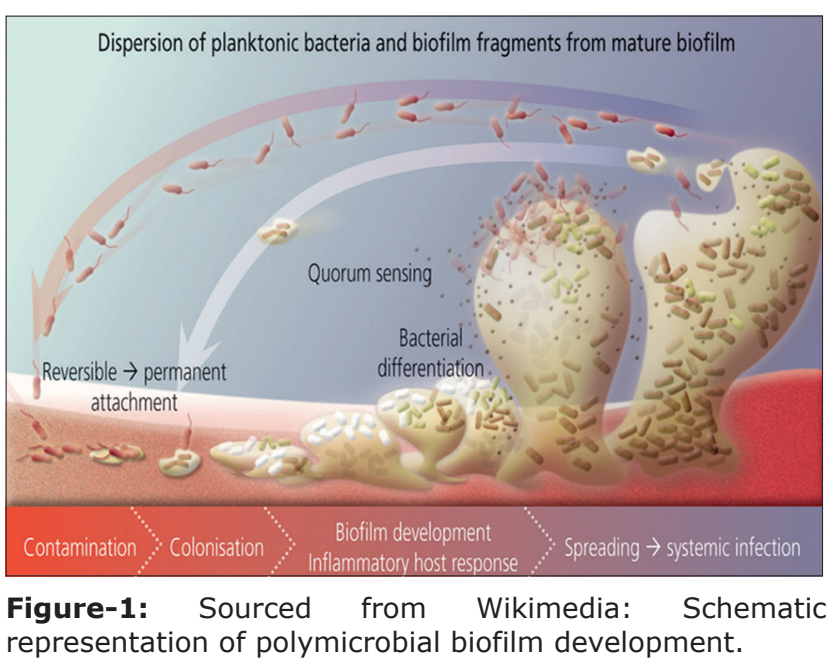

\section{Adhesion/attachment}

This is a crucial stage in biofilm formation involving attachment or adhesion of microorganism, the process occurs in two steps, reversible and irreversible adhesion [11,12]. Reversible adhesion (attachment) is an initial weak attachment of microbial cells to a surface while irreversible adhesion occurs as a permanent bonding of microorganisms to a surface. Attachment occurs reversibly due to the impact of either hydrodynamic or repulsive forces; it can also be as a result of a response to the absence of nutrient availability [1215]. Cellular and extracellular appendages play a vital role in microbial surface attachment. The common appendages often used in bacterial attachment to plant and animal tissues surfaces include pili and fimbriae, which consist of multiple different appendages, and other structures such as curli, adhesins, intimins, and invasins [16-19].

Attachment of bacteria has been found to stimulate expression of numerous genes that activate release of extracellular matrix and subsequent development of biofilm $[11,20]$. Thus, biofilm formation progresses when bacteria adhere to surfaces in aqueous environment and begin to excrete a slimy glue-like substance that can anchor them to a variety of materials including, metals, plastics, soil particles, medical implant materials and most significantly animal or human tissue [21], Figure-1 illustrates how biofilm attachment takes place.

\section{Growth and Development/Microcolonies Formation}

Microbial growth, development of microcolonies and recruitment of additional microorganisms occurs after adsorption of macromolecules and attachment of microbial cells to a substratum. Subsequently, after the initial colonization, the biofilm grows through a combination of cell division and recruitment. Microcolonies are three to five layers deep community of bacterial cell [22]. As the attachment of microorganism occurs, the colonizing bacteria grow with the production and accumulation of extracellular polymers. Consequently, the cells are dependent on substrate flux from the liquid phase and/or exchange of nutrient with neighboring cells in the biofilm [11]. It is important to note that mere attachment of microorganism to a surface does not imply the formation of microcolony, hence, a coherent cell to cell interactions are needed to establish and hold the microcolony together [23].

\section{Detachment/dispersal}

Detachment of cells from the biofilm colony and their dispersal into the environment marks the final and indeed an essential stage of biofilm life cycle; this contributes to biological dispersal, bacterial survival, and disease transmission. Like other stages of biofilm development, dispersal can be a complex process involving numerous environmental signals, signal transduction, pathways and effectors [24]. To date, detachment remains poorly researched and understood, which therefore, complicates the formation of satisfactory models [11]. Biofilm detachment can also occur as a result of a low nutrient condition indicating a homeostatic mechanism, which may be genetically determined. Therefore, detachment is not just important for promoting genetic diversity, but also escaping unfavorable habitat aiding in the development of new niches [11].

Thus, once biofilms are established planktonic bacteria may periodically leave biofilm on their own and when they do, they can rapidly multiply and disperse. The dispersal or shedding of planktonic cells from a biofilm may be essential to permit bacteria escape from confines of the biofilm in order to colonize new locations [1].

Bacterial dispersal can be divided into three distinct phases; (i) Detachment of cells from the biofilm 
colony, (ii) Translocation of the cells to new locations, (iii) Attachment of cells to a substrate in the new location [25]. In general, mechanisms of biofilm dispersal can be divided into two broad categories which are; active and passive dispersal. Active dispersal refers to mechanisms that are initiated by the bacteria themselves, whereas passive dispersal refers to biofilm cell detachment that is mediated by external forces such as fluid shear, abrasion (collision of solid particles with the biofilm), predator grazing, animal and human intervention [26,27], Figure-1 illustrates how dispersal pattern of biofilm and planktonic bacteria are exhibited.

\section{Microbial Food Contact Surface in Veterinary Medicine}

Under favorable conditions, an array of existing spoilage and pathogenic microorganisms frequently comes in contact with various surfaces within animal habitats. This consequently, poses a serious challenge in the animal and human food industry. Common microbial contact surfaces in the livestock industry includes, animal feeding troughs, drinkers, and other routinely used glass, plastic and polypropylene utensils $[28,29]$. Thus, contact of spoilage and pathogenic microbes with these surfaces can result in biofilm formation, causing spoilage of food as well as various pathological conditions in animal [28-30].

The most common microbial food contact surfaces leading to food spoilage are Pseudomonas fragi, Pseudomonas aeruginosa, Micrococcus spp. and Enterococcus faecium while the likes of Listeria monocytogenes, Yersinia enterocolitica, Staphylococcus aureus, Salmonella typhimurium and E. coli, belongs to the pathogenic class [31-33]. Biofilm has also been found in several contact surfaces available in diary plants. Microbes like, Streptococcus spp., Shigella spp. and E. coli often comes in contact either directly with the animals or milking equipment, resulting in the development of biofilm [34,35]. However, this causes contamination of the dairy products and diseases among affected animals, as well as serving as potential zoonosis [36,37].

\section{Biofilm Antimicrobial Resistance in Veterinary Medicine}

The ability of bacterial pathogens to resist adverse conditions, while inflicting damage on its host depends on the capacity to form biofilm [2]. Biofilm are much more resistant to antimicrobial agents when compared to free-flowing planktonic bacteria, in most cases, over a thousand times more concentration of an antibiotics required to kill planktonic bacteria will be needed to destroy biofilm bacteria [1,38]. Multi species biofilm are more resistant to antimicrobial agents, although some genetically heterozygous single species biofilms are highly resistant to antimicrobial therapy as well as the host immune response. Restriction of antimicrobial agents from gaining access to the pathogens due to the impervious nature of the biofilm encased extracellular matrix, plays a pivotal role in biofilm antimicrobial resistance [39].

Strong protection is conferred on biofilm organisms by the encapsulating self-produced extracellular polymeric substances, this substances keeps biofilm extracellular enzymes in proximity to the cells $[2,40]$. Enzymes produced by biofilm polymeric substances plays a key role in protecting the bacteria organism through metabolizing of biopolymers and other substances used as antimicrobial agents [40,41]. Common extracellular enzymes produce by the biofilm polymeric substance are aminoglycoside modifying enzymes (AMEs) and beta-lactamase $[42,43]$. This property is posed by Acitenobacter baumannii, a short and rod-shaped Gram-negative bacterium belonging to the "ESKAPE" group of pathogens known for causing serious nosocomial infection among hospitalized animals and humans [44]. High aminoglycoside resistivity exhibited by these pathogens is mainly due to AME produced by the bacterial biofilm $[42,45]$. As revealed in various researches, animal and human pathogenic bacteria that produces beta-lactamase enzyme are referred to as beta-lactam producing bacteria (BLPB) [46]. These classes of bacterial organisms are responsible for a number of antimicrobial resistant biofilm infections in veterinary medicine $[43,46]$. Example of animal derived BLPB are Salmonella spp., E. coli, Enerococcus spp., Campylobacter spp., and Staphylococcus spp among others [43]. This enzyme inhibits the antimicrobial actions of beta-lactam antibiotics, as demonstrated in the inhibitory action of beta-lactamase to penicillin antibiotic [47].

The role of BLPB in promoting biofilm resistance against beta-lactam among non-BLPB pathogens have been demonstrated in an in vitro study showing resistance of non-BLPB to penicillin owing to the release of beta-lactamase enzyme within the environment [47], perhaps this throws more light on the concept of multi species biofilm antimicrobial resistivity. Recently, another common case of biofilm antimicrobial resistance was demonstrated in a study, revealing the development of $E$. coli biofilm in canine urinary tract infection and resistance of the condition to fluroquinolones therapy [48]. According to a recent study conducted on the detection of virulence among strains of coagulase negative Streptococcus (CNS), reveals a strong connection between presence of certain genes that promotes virulence among the highly pathogeneic strains of CNS biofilm [49]. Similarly, in two separate studies, virulence genes (hlyA, plcA, actA, and iap) responsible for pathogenicity of listeria monocytogens was identified in milk of goats, sheep and camels which potentially poses a great zoonotic threat to human, when such dairy products are consumed [50,51]. Hence, understanding the genetic mechanism of biofilm development would be of great importance in interfering with formation of biofilm. Generally, biofilm resistance to antimicrobials 
explains the puzzling nature of urinary tract infection in both animals and humans, occurring mostly as a recurrent infection $[48,52]$.

\section{Diagnostic and Therapeutic Approach of Biofilm Infection in Veterinary Medicine}

As a rule of thumb, effective treatment of any disease requires accurate diagnosis of the disease [53]. However, due to the complex nature of biofilm, achieving accurate diagnosis through the conventional culture and isolation diagnostic method is quite difficult $[53,54]$. Adherence of microbes to specific parts of an animal host often results in negative culture result, in some cases false positive result is obtained due to the presence of free moving planktonic bacteria. Therefore, diagnostic approach tailored toward identifying specific microbes will be most appropriate for biofilm diagnosis.

At present, diagnostic techniques such as; serology, fluorescent in situ hybridization, conventional radiographic approaches (computed tomography, magnetic resonance imaging and radioinuclide scans), polymerase chain reaction, loop-mediated isothermal amplification and other molecular technique has shown promising result in effectively diagnosing biofilm diseases [53-57]. Use of non-invasive microscopic imaging technique known as laser scanning confocal microendoscopy has been successfully used in diagnosis of mucosal biofilm infection. This laser scanning method promotes easy observation of biofilm in mucosal biofilm of hollow organs such as the lower gastrointestinal tract, middle ear and the urinary tract [56]. Use of specific biofilmvirulence gene markers, will not only be a useful tool of identifying biofilm but exposes the presence of certain virulent biofilm in clinical samples, a good example is identification of the genes in milk of cows suffering from mastitis [50,51].

Effective treatment of biofilm infection requires dual approach through combination of antibiofilm and antimicrobial agent [58]. The pathophysiology of biofilm infection is thought to be regulated by the quorum sensing mechanism, through a cascade of event in which community of microorganism, united as a single entity expresses gene virulence, and the antimicrobial properties [59-61]. Proper understanding of the concept of quorum sensing phenomenon is key toward developing an effective means of combating biofilm. Conventional antimicrobial approach has a restricted range of action against fast growing pathogenic organism with little or no effect on biofilm [62]. However, more radical therapeutic approach, involving the combination of conventional antimicrobial with devices like:

\section{Ultrasound}

This device enhances the bacteriocidal action of the antimicrobial agent, through passage of non-invasive acoustic energy waves through the skin to the site of biofilm [62]. Ultrasonic energy is also used to enhance the release of drug from delivery devices, and elicits antimicrobial action by promoting biofilm cellular membrane destruction, hence enables active or passive uptake of antibiotics [62].

\section{Electric current}

Synergetic use of low level electric current with antibiotics enhances the antimicrobial activity of antibiotic which ordinarily are resisted to by biofilm organism(s) [62-64]. The electromagnetic pulse will increase the antimicrobial activity of cationic antibiotics against bacterial biofilm, example is the simultaneous release of electromagnetic impulse with administration of gentamicin against $S$. aureus [62].

\section{Phage therapy}

This is a robust therapeutic approach, although not commonly employed in veterinary biofilm therapeutics, it however, involves the use of protein that encapsulates DNA or RNA genome to elicit strong bacteriocidal actions at the site of a biofilm infection. The mechanism through which phage achieves its antibiofilm action is by enzyme production which hydrolyses and degrades the extracellular matrix of biofilm, perhaps, the use of bacteriophage or combination with antibiotic will be effective $[65,66]$.

\section{Drug delivery system}

This system involves combination of antimicrobial drugs with nano-carriers. Antimicrobials such as gentamycin, ampicilin, ciprofloxacin among others are encapsulated in a drug delivery nano-carrier. Examples of commonly used nano-carriers include phosphotydyl-choline, polyethylene glycerol, polyamidoamine, and polyacrylate. Mechanism of action of nano-carrier is basically through prolonging the action of the active molecules which is been delivered to the appropriate action site, this approach has proved effective against biofilm [62].

\section{Conclusions}

Additional research is needed to unravel the mystery of biofilm. Present trend of biofilm in veterinary medicine suggest persistence of animal and human health challenges in the future, leading to greater economic loss. Strict adherence to aseptic practice in the livestock industry will go a long way in stemming the menace of biofilm. Control of illicit and indiscriminate use of antibiotics, will also help to address some of the challenges posed by biofilm antibiotic resistance. Application of novel therapeutic approach such as, phage therapy and the use of some mucolytic agents that is capable of inhibiting biofilm formation, are highly recommended. Effort should be targeted at interfering with development of biofilm rather than focusing on treatment which is often difficult to achieve, this can be realized through improved studies on the genetic mechanism of biofilm development. Furthermore, combination of antibiotics with certain devices like the nano-carriers, ultrasound and other recent technology, which uses controlled level 
of electric current in promoting antibacterial activity of antibiotics has shown promising result.

\section{Authors' Contributions}

UFA, EI and AM conceived the idea and design. Assembling of resource was done by UFA, AM, and SA. All the authors contributed in the drafting and editing of the manuscript. All authors read and approved the final manuscript.

\section{Acknowledgments}

The authors acknowledge the management and staff of the Faculty of Medicine, Universiti Sultan Zainal Abidin for their support.

\section{Competing Interests} interests.

The authors declare that they have no competing

\section{References}

1. Costeron, J.W., Stewart, P.S. and Greenberg, E.P. (1999) Bacterial biofilms: A common cause of persistent infections. Science, 284: 1318-1322.

2. Clutterbuck, A.L., Woods, E.J., Knottenbelt, D.C., Cleqq, P.D., Cochrane, C.A. and Percival, S.L. (2007) Biofilms and their relevance to veterinary medicine. Vet. Microbiol., 125(3-4): 390.

3. Garcia, A.B. and Percival, S.L. (2011) Zoonotic infections: The role of biofilm. Biofilm Vet. Med., 6: 69-110.

4. Zambori, C., Tirziu, E., Nichita, I., Cumpanasoiu, C., Gros, R.V., Seres, M., Mladin, B. and Mot, D. (2012) Biofilm implication in oral diseases of dogs and cats. Anim. Sci. Biotechnol., 45(2): 208.

5. Nam, E.H., Ko, S., Chac, J.S. and Hwang, C.Y. (2013) Characterization and zoonotic potential of uropathogenic Escherichia coli isolated from dogs. J. Microbiol. Biotechnol., 23(3): 422-429.

6. Stoodley, P., Sauer, K., Davies, D.G. and Costerton, J.W. (2002) Biofilms as complex differentiated communities. Annu. Rev. Microbiol., 56(1): 187-209.

7. Sauer, K., Cullen, M.C., Rickard, A.H., Zeef, L.A.H., Davies, D.G. and Gilbert, P. (2004) Characterization of nutrient-induced dispersion in Pseudomonas aeruginosa PAO1 biofilm. J. Bacteriol., 186(21): 7312-7326.

8. McDougald, D., Klebensberger, J., Tolker-Nielsen, T., Webb, J.S., Conibear, T., Rice, SA. and Kjelleberg, S. (2008) Pseudomonas aeruginosa: A model for biofilm formation. Pseudomonas: Model Organism, Pathogen, Cell Factory, Wiley-VCH, Weinheim. p215-253.

9. Chamberlain, A.H.L. (1992) The role of adsorbed layers in bacterial adhesion. In: Biofilms: Science and Technology. Springer, Netherlands. p59-67.

10. Rittle, K.H., Helmstetter, C.E., Meyer, A.E. and Baier, R.E. (1990) Escherichia coli retention on solid surfaces as functions of substratum surface energy and cell growth phase. Biofouling, 2(2): 121-130.

11. Percival, S.L., Malic, S., Cruz, H. and Williams, D.W. (2011) Introduction to biofilms. In: Biofilms and Veterinary Medicine. Springer, Berlin, Heidelberg. p41-68.

12. Wu, Y. and Outten, F.W. (2009) IscR controls iron-dependent biofilm formation in Escherichia coli by regulating type I fimbria expression. J. Bacteriol., 191: 1248-1257.

13. Singh, A., Walker, M., Rousseau, J. and Weese, J. (2013) Characterization of the biofilm forming ability of Staphylococcus pseudintermedius from dogs. BMC Vet. Res., 9: 93.

14. Banin, E., Vasil, M.L. and Greenberg, E.P. (2005) Iron and
Pseudomonas aeruginosa biofilm formation. Proc. Natl. Acad. Sci., 102: 11076-11081.

15. Anderson, G.G., Moreau-Marquis, S., Stanton, B.A. and O'Toole, G.A. (2008) In vitro analysis of tobramycin-treated Pseudomonas aeruginosa biofilms on cystic fibrosis-derived airway epithelial cells. Infect. Immun., 76: 1423-1433.

16. Kim, T., Young, B.M. and Young, G.M. (2008) Effect of flagellar mutations on Yersinia enterocolitica biofilm formation. Appl. Environ. Microbiol., 74: 5466-5474.

17. Kline, K.A., Falker, S., Dahlberg, S., Normark, S. and Henriques-Normark, B. (2009) Bacterial adhesins in host-microbe interactions. Cell Host Microbe, 5: 580-592.

18. Pizarro-Cerdá, J. and Cossart, P. (2006) Bacterial adhesion and entry into the host cell. Cell, 124: 715-727.

19. Spurbeck, R.R., Stapleton, A.E., Johnson, J.R., Walk, S.T., Hooton, T.M. and Mobley, H.L. (2011) Fimbrial profiles predict virulence of uropathogenic Escherichia coli strains: Contribution of ygi and yad fimbriae. Infect. Immun., 79(12): 4753-4763.

20. Sauer, K., Camper, A.K., Ehrlich, G.D., Costerton, J.W. and Davies, D.G. (2002) Pseudomonas aeruginosa displays multiple phenotypes during development as a biofilm. $J$. Bacteriol., 184(4): 1140-1154.

21. Proal, A. (2008) Understanding biofilms. Bacteriality: Exploring Chronic Disease. http://bacteriality. com/2008/05/26/biofilm. Accessed on 10-07-2015.

22. Davey, M.E. and O'toole, G.A. (2000) Microbial biofilms: From ecology to molecular genetics. Microbiol. Mol. Biol. Rev., 64(4): 847-867.

23. Reisner, A., Haagensen, J.A., Schembri, M.A., Zechner, E.L. and Molin, S. (2003) Development and maturation of Escherichia coli K-12 biofilms. Mol. Microbiol., 48(4): 933-946.

24. Karatan, E. and Watnick, P. (2009) Signals, regulatory networks, and materials that build and break bacterial biofilms. Microbiol. Mol. Biol. Rev., 73(2): 310-347.

25. Kaplan, J.Á. (2010) Biofilm dispersal: Mechanisms, clinical implications, and potential therapeutic uses. J. Dent. Res., 89(3): 205-218.

26. Choi, Y.C. and Morgenroth, E. (2003) Monitoring biofilm detachment under dynamic changes in shear stress using laser-based particle size analysis and mass fractionation. Water Sci. Technol., 47(5): 69-76.

27. Ymele-Leki, P. and Ross, J.M. (2007) Erosion from Staphylococcus aureus biofilms grown under physiologically relevant fluid shear forces yields bacterial cells with reduced avidity to collagen. Appl. Environ. Microbiol., 73(6): 1834-1841.

28. Parizzi, S.Q.F. (1999) Adherence of bacteria on different surfaces appraised by Microscopia of Epifluorescência \& Count in slabs. Lush, Brazil. (M.Sc. Dissertation. Science \& Tecnology of Foods UFV ).

29. Pompermayer, D.M.C. and Gaylarde, C.C. (2000) The influence of temperature on the adhesion of mixed cultures of Staphylococcus aureus and Escherichia coli to polypropylene. Food Microbiol., 17(4): 361-365.

30. Wirtanen, G., Helander, I.M. and Matilla-Sandholm, T. (2000) Microbial methods for testing disinfectant efficiency on Pseudomonas biofilm. Colloids Surf. B Biointerfaces, 20(1): 37-50.

31. Zottola, E.A. and Sasahara, K.C. (1994) Microbial biofilms in the food processing industry - Should they be a concern? Int. J. Food Microbiol., 23(2): 125-148.

32. Perron, G.G., Zasloff, M. and Bell, G. (2006) Experimental evolution of resistance to an antimicrobial peptide. Proc. $R$. Soc. B Biol. Sci., 273: 251-256.

33. Ruggeri, V., Francolini, I., Donelli, G. and Piozzi, A. (2007) Synthesis, characterization, and in vitro activity of antibiotic releasing polyurethanes to prevent bacterial resistance. J. Biomed. Mater. Res., 81: 287-298. 
34. Flint, S.H., Bremer, P.J. and Brooks, J.D. (1997) Biofilms in dairy manufacturing plant - description, current concerns and methods of control. Biofouling, 11: 81-97.

35. Cervinkova, D., Volka, A., Borodacova, I., Mako Conencova, A., Vrtkova, I., Babak, V., Marosevic, D. and Taglic, Z. (2013) Prevalence of mastitis pathogens in milk from cow clinically healthy cows. Vet. Med., 58(11): 567-575.

36. Parkar, S., Flint, S., Teh, K.H., Brooks, J. and Bremer, P. (2015) Pathogen contamination in dairy manufacturing environments. In: Biofilms in the Dairy Industry. John Wiley \& Sons, Ltd., Chichester, UK.

37. Asao, T., Kumeda, Y., Kawai, T., Shibata, T., Oda, H., Haruki, K., Nakazawa, H. and Kozaki, S. (2003) An extensive outbreak of Staphylococcal food poisoning due to lowfat milk in Japan: Estimation of enterotoxin A in the incriminated milk and powdered skim milk. Epidemiol. Infect., 130: 33-40.

38. Costerton, J.W., Veeh, R., Shirtliff, M., Pasmore, M., Post, C. and Ehrlich, G. (2003) The application of biofilm science to the study and control of chronic bacterial infections. J. Clin. Invest., 112:1466-1477.

39. Percival, S.L. and Bowler, P.G. (2004) Biofilm and the potential role in wound healing. Wounds, 16: 234-240.

40. Meyle, E., Stroh, P. and Gunther, F. (2010) Destruction of bacterial biofilms by polymorphonuclear neutrophils: Relative contribution of phagocytosed DNA release and degranulation. Int. J. Artif Organs, 33: 608-620.

41. Ghafoor, A., Hay, I.D. and Rehm, B.H. (2011) Role of exopolysacharides in Pseudomonas aeruginosa biofilm architecture. Appl. Environ. Microbiol., 77: 5238-5246.

42. Seward, R.J., Lambert, T. and Tourner, K.J. (1998) Molecular epidemiology of Aminoglycoside resistance in Acinetobacter spp. J. Med. Microbiol., 47: 455-462.

43. Qin, S., Wang, Y., Zhang, Q., Chen, X., Shen, Z., Deng, F., $\mathrm{Wu}, \mathrm{C}$. and Shen, J. (2012) Identification of a novel genomic island conferring resistance to multiple aminoglycoside antibiotics in Campylobacter coli. Antimicrob. Agents Chemother., 1(56): 5332-5339.

44. Rice, L.B. (2008) Federal funding for the study of antimicrobial resistance in nosocomial pathogens: ESKAPE. $J$. Infect. Dis., 197(8): 1079-1081.

45. Alice, J.G., Percival, S.L. and Cochrane, C.A. (2011) Biofilms and role to infection and disease in veterinary medicine. Life Sci. Microbiol., 6: 111-128.

46. Hoiby, N., Bjarnsholt, T., Givskov, M., Molin, S. and Ciofu, O. (2010) Antibiotic resistance of bacterial biofilms. Int J Antimicrob Agents, 35(4): 322-332.

47 Brook, I. (2009) The role of beta lactamase producing bacteria in mixed infections. BMC Infect. Dis., 9: 202.

48 Oliviera, M., Dias, F.R. and Pomba, C. (2014) Biofilm and fluroquinolone resistance of canine Escherichia coli uropathogenic isolates. BMC Res. Notes., 7: 499.

49 Osman, K.M., Abd El-Razik, K.A., Marie, H.S.H. and Arafa, A. (2015) Relevance of biofilm formation and virulence of different species of coagulase-negative staphylococci to public health. Eur. J. Clin. Microbiol. Infect. Dis., 34(10): 2009-2016.

50 Kamelia, M.O., Tara, R.Z, Ahmed, S. and Ahmed, O. (2014) Prevalence, pathogenic capability, virulence genes, biofilm formation, and antibiotic resistance of Listeria in goat and sheep milk confirm need of hygienic milking conditions. Pathog. Glob. Health., 108(1): 21.

51 Kamelia, M.O., Ahmed, S., Ahmed, O. and Tara, R.Z. (2014) Confirmed low prevalence of Listeria mastitis in she-camel milk delivers a safe, alternative milk for human consumption. Acta. Trop., 130(2014): 1-6.

52 Johnson, J.R., Owens, K., Gajewski, A. and Clabots, C. (2008) Escherichia coli colonization patterns among human household members and pets, with attention to acute urinary tract infection. J. Infect. Dis., 197: 218-224.

53 Abdullahi, U.F., Naim, R, ALiyu, S., Mu'azu, A., WanTaib, W.R., Saleh, A. and Baig. A.A. (2015) Loop-mediated isothermal amplification (LAMP), an innovation in gene amplification: Bridging the gap in molecular diagnostics; a review. Indian J. Sci. Technol., 9(12): 55767.

54 Anastasiadis, P., Mojica, K.D.A., Allen, J.S. and Matter, M.L. (2014) Detection and quantification of bacterial biofilms combining high-frequency acoustic microscopy and targeted lipid microparticles. J. Nanobiotechnol., 12: 24 .

55 Dongari-Bagtzoglou, A. (2008) Pathogenesis of mucosal biofilm infections: Challenges and progress. Expert Rev. Anti-Infect. Ther., 6(2): 201-208.

56 Brady, R.A., Leid, J.G., Camper, A.K., Costerton, J.W. and Shirtliff, M.E. (2006) Identification of Staphylococcus aureus proteins recognized by the antibody-mediated immune response to a biofilm infection. Infect. Immun., 74: 3415-3426.

57 Segall, G.M., Nino-Murcia, M., Jacobs, T. and Chang, K. (1989) The role of bone scan and radiography in the diagnostic evaluation of suspected pedal osteomyelitis. Clin. Nucl Med., 14: 255-260.

58 Römling, U. and Balsalobre, C. (2012) Biofilm infections, their resilience to therapy and innovative treatment strategies. J. Intern. Med., 272(6): 541-561.

59 Sifri, CD. (2008) Healthcare epidemiology: Quorum sensing: Bacteria talk sense. J. Clin. Infect. Dis., 47: 1070-1076.

60 Van Houdt, R., Givskov, M. and Michiels, C.W. (2007) Quorum sensing in Serratia. FEMS Microbiol. Rev., 31(4): 407-424.

61 Schillaci, D. and Vitale, M. (2012) Biofilm related to animal health, zoonosis and food transmitted diseases: Alternative target for antimicrobial strategy. J. Micobiol. Biochem. Technol., 4: 7-10.

62 Kasimanickam, R.K., Ranjan, A., Asokan, G.V., Kasimanickam, V.R. and Kastelic, J.P. (2013) Prevention and treatment of biofilms by hybrid- and nanotechnologies. Int. J. Nanomed., 8: 2809-2819.

63 Borriello, G., Werner, E., Roe, F., Kim, A.M., Ehrlich, G.D. and Stewart, P.S. (2004) Oxygen limitation contributes to antibiotic tolerance of Pseudomonas aeruginosa in biofilms. Antimicrob Agents Chemother., 48(7): 2659-2664.

64 Pickering, S.A., Bayston, R. and Scammell, B.E. (2003) Electromagnetic augmentation of antibiotic efficacy in infection of orthopaedic implants. J. Bone Joint Surg. Br., 85(4): 588-593.

65 Weiling, F.U., Forster, T., Mayer, O., Curtin, J.J., Lehman, S.M. and Donlan, R.M. (2010) Bacteriophage cocktail for the prevention of biofilm formation by Pseudomonas aeruginosa on catheters in an in vitro model system. Antimicrob Agents Chemother., 54(1): 397-404.

66 Verma, V., Harjai, K. and Chhibber, S. (2010) Structural changes induced by a lytic bacteriophage make ciprofloxacin effective against older biofilm of Klebsiella pneumoniae. Biofouling, 26(6): 729-737.

67 Zadoks, R.N., Middleton, J.R., McDougall, S., Katholm, J. and Schukken, Y.H. (2011) Molecular epidemiology of mastitis pathogens of dairy cattle and comparative relevance to humans. J. Mammary Gland Biol. Neoplasia, 16(4): 357-372.

68 Melchior, M.B., Fink-Gremmels, J. and Gaastra, W. (2006a) Comparative assessment of the antimicrobial susceptibility of Staphylococcus aureus isolates from bovine mastitis in biofilm versus planktonic culture. J. Vet. Med. Series B Infect. Dis. Vet. Public Health., 53: 326-332.

69 Melchior, M.B., Vaarkamp, H. and Fink-Gremmels, J. (2006b) Biofilms: A role in recurrent mastitis infections? Vet. J., 171: 398-407.

70 Singh, A.V., Singh, S.V., Singh, P.K., Sohal, J.S, Swain, N, Rajindran, A.S. and Vinodh, O.R. (2009) Multiple tests based prevalence estimates of Mycobacterium avium sub specie Paratuberculosis infection in elite farms of goats and sheep. Indian J. Small Rumin., 15: 178-182.

71 Lombard, J.E., Gardner, I.A., Jafarzadeh, S.R., Fossler, C.P., 
Harris, B., Capsel, R.T., Wagner, B.A. and Johnson, W.O. (2013) Herd-level prevalence of Mycobacterium avium sub specie Paratuberculosis infection in United States diary-herds. Prev. Vet. Med., 108(2-3): 234-238.

72 Olson, M.E., Ceri, H., Morck, D.W., Buret, A.G. and Read, R.R. (2002) Biofilm bacteria: Formation and comparative susceptibility to antibiotics. Can. J. Vet. Res., 66(2): 86-92.

73 Bastos, B.L., Dias Portela, R.W., Dorella, F.A., Ribeiro, D., Seyffert, N., Luiz de Paula, T., Miyoshi, A., Oliveira, S.C., Meyer, R. and Azevedo, V. (2012) Corynebacterium pseudotuberculosis: Immunological responses in animal models and zoonotic potential. J. Clin. Cell. Immunol., S4: 005.

74 Tadepalli, S., Narayanan, S.K., Stewart, G.C., Chengappa, M.M. and Nagaraja, T.G. (2009) Fusobacterium necrophorum: A ruminal bacteria that invades liver to cause abscesses in cattle. Anerobes, 15(1-2): 36-43.
75 Westgate, S.J., Percival, S., Knottenbelt, D.C., Clegg, P.D. and Cochrane, C.A. (2010) Chronic equine wounds: What is the role of infection and biofilms? Wounds, 22(6): 138-147.

76 Hennig, G.E., Kraus, B.H., Fister, R., King, V.L., Steckel, R.R. and Kirker-Head, C.A. (2001) Comparison of two methods for pre-surgical disinfection of the equine hoof. J. Vet. Surg., 30:366-373.

77 Chen, Y.M., Wright, P.J., Lee, C.S. and Browning, G.F. (2003) Uropathogenic virulence factors in isolates of Escherichia coli from clinical cases of canine pyometra and feces of healthy bitches. Vet. Microbiol., 94: 57-69.

78 Hagman, R. and Kuhn, I. (2002) Escherichia coli strains isolated from the uterus and urinary bladder of bitches suffering from pyometra: Comparison by restriction enzyme digestion and pulsed-field gel electrophoresis. Vet. Microbiol., 84: 143-153.

$* * * * * * * *$ 